\begin{abstract}
$\ddot{O} z$
İnsan sınırlı istidatlara sahip olduğundan her konuyu bütün incelikleriyle bilme imkânına sahip değildir bu yüzden herhangi bir konu hakkında yanlış karar vermekten sakınmak ve başarıyı elde etmek için başkalarıyla meşveret etmek zorundadır. Meşveret; hak ve hakikati ortaya koyup, mevcut şartlar içinde yapılması gerekenin isabetli şekilde belirleme imkânı verir. Meşveret kavramının ehemmiyetini iyi şekilde kavrayan büyük mütefekkirlerden Mevlânâ, Mesnevî'sinde çeşitli vesilelerle meşveret kavramına değinip, meşveretin sosyal ve ahlaki usullerden biri olduğunu vurgulayıp, meşveretin gerekli olduğunu birçok Mesnevî defterinde belirtmiştir. Meşveret, Mesnevî’de hem âfâkî hem de enfüsî olarak ele alınmıştır.
\end{abstract}

Anahtar Kelimeler: Mevlânâ, Mesnevî, Meşveret,

\title{
Consultancy in Mathnawi
}

\begin{abstract}
Because human has limited capability, he/she does not have the opportunity to know each subject with all the subtlety. So, to avoid the wrong decisions on any matter and to achieve success he/she has to have a consultation with others. Consultation reveals the right and the truth, and has the ability to determine what to do in the existing conditions accurately. Mawlana -of the great thinkers- who understood so well the significance of the concept of consultation referred to the concept of consultation on several occasions in his Mathnawi. He emphasized that consultation is one of the social and ethical procedures and that it is required in the social relations in many Mathnawi books.
\end{abstract}

Key Words: Mawlana, Mathnawi, Consultancy.

* Arş. Gör., İstanbul Üniversitesi Fars Dili ve Edebiyatı Bölümü e-mail: cetinkaska@hotmail.com 


\section{Giriş}

Meşveret, sözlükte "danışma, görüş alışverişinde bulunma ve konuşup görüşme” anlamlarına gelmektedir. İslami literatürde yönetici ve devlet başkanının görev alanına giren işler hakkında ilgili kişilere danışıp onların görüşlerini dikkate almasını ifade etmektedir. Meşveret, şûra, istişâre ve müşâvere ile aynı anlama gelmektedir. ${ }^{1}$ Meşveret ile ilgili Kur'an-ı Kerim'de iki meşhur ayet vardır. Birisi Âl-i İmrân sûresinin 159.cu ayetidir: (İşs konusunda onlarla müşâvere et...) Bu ayette Hazret-i peygambere iş konusunda müminlerle istişâre edilmesi emredilmiştir. Diğer ayet ise Şûrâ sûresinin 38.ci (Onların işleri kendi aralarında meşveret iledir...) ayetidir. Bu ayette ise Müslümanların istişâre ile emrolundukları vurgulanmıştır. ${ }^{2}$ Meşverete önem veren peygamberimiz hemen her hususta ashabıyla meşveret eder onların görüşlerini alırdı. Nitekim Ebu Hüreyre peygamberimizin bu yönüyle ilgili şu tespitte bulunmuştur; "Ben, Resulullah'tan daha fazla arkadaşlarıyla meşveret eden birini görmedim." ${ }^{3}$ Ayrıca hadislerde şûra, meşveret, istişâre gibi kelimeler sözlük anlamlarıyla sıkça geçmektedir.

İslam tarihi süresince Müslümanlar tarafında kurulan devletlerde padişaha danışmanlık yapan çeşitli kurular oluşturulmak suretiyle meşveret sistemi işletilmiştir. Özellikle Emevîler döneminden başlayarak, şûra yöneticiler, ordu komutanları ve ilim adamlarının katılımıyla genel ya da özel olarak yapılmıştır. ${ }^{4}$

Mevlânâ meşveret etmeyi ahlâkî ve sosyal usullerden biri görüp meşverettin bir gereklilik olduğunu Mesnevî’nin bütün defterlerinde ayet ve hadislere işaret ederek dile getirmiştir. Meşveret sayesinde hataların azaldığı, emin ve düşünceli kimselerle meşveret etmenin önemli olduğunu ifade etmiş̧tir. Mesnevî’de meşveretin âfâkî ve enfüsî olmak üzere iki şekilde ele alındığı görülmektedir.

\section{Mesnevî'de Meşveret İle İlgili Genel İlkeler}

\section{A-Meşveret Gereklidir}

İşlerde meşveretin gerekli olduğunu belirten Mevlânâ, meşveret sayesinde pişmanlık, hayal kırıklığı, hüsran ve fiyaskonun önüne geçildiğini ve sonunda pişman olmamak veya az zararla kurtulmak için işlerde müşâverede bulunmak gerektiğini beyan etmiştir. ${ }^{5}$

1 Talip Türcan, "Şûra” DİA, c.39, İstanbul 2010, s. 230.

2 Kerîm Zemânî, Mînâger-i Işk, Neşr-1 Ney, Tahran 1393, s.825.

3 Tirmizi, Cihat 35.

4 Türcan, a.g.m, s. 231.

5 Şefik Can, Konularına Göre Açıklamamalı Mesnevî Tercümesi, Ötüken Yayınları c.1-2, s. 432 İstanbul 1997. 


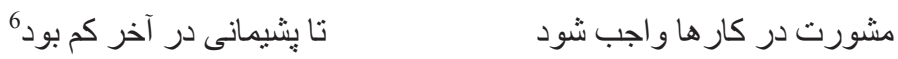

İşin sonunda pişman olma riskini azaltmak için işlerde meşveret etmek vacibdir.

Mevlânâ'ya göre kişi ne kadar akıllı olursa olsun ve ne kadar tecrübe kazanırsa kazansın mutlaka başka biriyle meşveret etmelidir. Nitekim peygamber efendimize "İşlerde ashab-ı kirâm ile meşveret et" emri gelmiş. İki aklın ortaya koyduğu ürünün daha etkili olduğu ve kişiyi belalardan kurtardığı ve meşveret sayesinde kişinin terakki ettiği vurgulamıştır. ${ }^{8}$

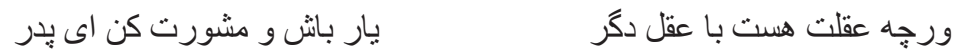

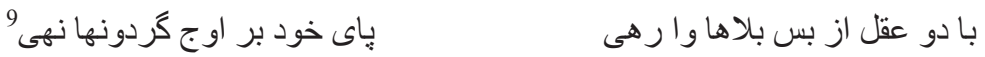

Ey peder! Eğer aklın varsa, başka bir akılla dost ol ve onunla meşveret et

İki akıl sayesinde birçok beladan kurtulur, göklerin doruğuna ayağını koyar$\sin$

\section{B-Meşveret Yapılırken Fikirlere Önem verilmeli}

Mevlânâ meşveret ederken, kişi yapmak istediğini açıkça ortaya koymamalı, asıl maksat gizlenerek muhatapların fikri alınmalı fakat bu yapılırken güzel, şaşırtıcı ve yanıltıcı açıklamalarla diğer kişilere ipucu verilmemesi gerektiğini ifade etmektedir. Mevlânâ peygamber efendimizin bir mesele hakkında meşveret ederken meseleyi üstü kapalı bir şekilde ortaya koyduğunu, yakınlarının görüşlerini aldığını ve fikir sahiplerinin işin aslını bilmeden düşüncelerini beyan ettiklerini dile getirmiştir. ${ }^{10}$

$$
\text { كرنته كنايت با غلطافكن مشوب }
$$

$$
\begin{aligned}
& \text { مشورت دارند سريوشيده خوب } \\
& \text { مشورت كردى ييمبر بستهر }
\end{aligned}
$$

6 Mevlânâ Celâleddin-i Rûmî, Mesnevî-i Ma’nevî, (haz. Adnan Karaismailoğlu, Derya Örs) b. 2256, c.2, s.325 Ankara 2007.

7 Halil Altuntaş- Muzaffer Şahin, Kur'ân-1 Kerim Meali, Diyanet İşleri Başkanlığı Yayınları, Âl-i İmrân, 3/159 Ankara 2003.

8 Abdülbaki Gölpınarlı, Mesnevî Tercümesi ve Şerhi, İnkılâp ve Aka Kitabevleri, c.3-4, s. 445 İstanbul 1983.

9 Mevlânâ, Mesnevî-i Ma'nevî, b. 1262, c.4, s.320.

10 H. Hüseyin Top, Mesnevî-i Mâ'nevî Şerhi, c.1, s.612, Konya 2001.

11 Mevlânâ, Mesnevî-i Ma'nevî, b.1052-53, c.1, s. 74. 
Meşvereti iyice gizli, başkalarını yanlışa düşürecek şekilde karışık kinaye içinde yaparlar.

Peygamber üstü kapall şekilde meşverette bulunurdu, onlar, ona cevap verir ama işin aslından haberleri olmazdl.

Bir müşkül karşısında akıllı kimselerle meşveret edilmesi tavsiyesinde bulunulmuş.

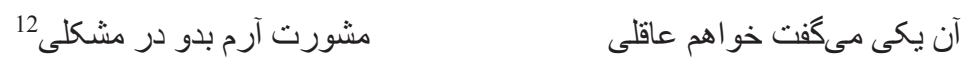

Biri; "Ben bir akıllı arıyorum, bir müşkülüm var onunla meşveret etmek istiyorum" dedi.

\section{C- Meşveret Yapılacak Kişinin Vasıffları}

Mevlânâ'ya göre istişâre edilecek ve fikri sorulacak kişi güvenilir, bilgin, emin, tedbirli, temkinli, yapıcı ve ileri görüşlü olmalıdır. Çünkü Hazret-i Peygamber bir hadîsinde; "Ey rey ve tedbir sahibi, istişârede bulun, zîrâ danışılan kişi emindir." buyurmuştur. ${ }^{13}$

$$
\text { كَت بيغامبر بكن اى راىزن }
$$

Peygamber; "Ey tedbir düşünen kişi, meşveret et çünkü danışılan kişi emindir" dedi.

Mevlânâ istişâre edilecek kişinin emin ve akıllı olması gerektiğini dile getirip bu konu hakkında bir hikâye anlatmıştır. Hikâyenin hülasası şöyle;

“Adamın biri bir türlü karar veremediği ve tereddütte kaldığ l bir konu hakkında kesin karar vermek için birisiyle istişâre etmek istedi fakat istişâre etmek istediği kişi ona "Bana güvenerek, benimle istişâre etmek için bana başvurman hoşuma gitti ancak ben senin dostun değilim sen başkasını bul onunla istişâre et. Ben senin düşmanınım benimle istişâre etme. Benim vereceğim akılla başarılı olamazsın. Git sana dost birisine danıs. Dost dostun hayrını ister şüphesiz! Ben düşmanım benim gibi birisinden sana fayda gelmez! Adam; Benim eski düşmanım olduğunu biliyorum fakat akıllı bir adamsın, aklın seni e ğri büğrü gitmeye bırakmaz. Akıl nefsin üstüne yürürse, onun intikam almasına engel olur” dedi. ${ }^{15}$

12 Mevlânâ, Mesnevî-i Ma'nevî, b.2326, c.2, s.328.

13 Top, a.g.e, s,608.

14 Mevlânâ, Mesnevî-i Ma'nevî, c.1, b. 1045, s. 73.

15 Mevlânâ, Mesnevî Ma'nevî, b. 1968, c.4, s.354. 
İstişâre edilecek kişinin o konu hakkında bilgi sahibi olması gerektiği vurgulanmıştır.

$$
\begin{aligned}
& \text { مشورت كن با يكى خاوندگًار } \\
& \text { اين جنين سوزان و كرم آخر مكار } \\
& \text { در خر ابى كرد ناخنها در از } 16 \\
& \text { مشورت كو عقل كو سيلاب آز }
\end{aligned}
$$

Sonunda böyle yakıcı ve sıcak ekin ekme, bir bilenle istişâre et.

İstişâre nerede? Akıl nerede? Hırs seli, tırnaklarını harap yere uzatır.

Mevlânâ’ya göre iyi düşünceli ve salih kimselerle meşveret edilme çünkü peygamber efendimize bile "Temiz kişilerle danıs,, onların fikirlerini sor" emri verildi. "İşlerini danışarak, müşâvere ederek yaparlar" ayeti bunun için inmiştir. Çünkü meşveret yapılan işte, yanılma daha az olur. Yirmi lamba elbette bir lambadan fazla nur verir. ${ }^{17}$

$$
\begin{aligned}
& \text { بر بيمبر امر شاور هم بدان } \\
& \text { كز تثاور سهو و كز كمنر رود } \\
& \text { مشورت كن با كروه صالحان } \\
& \text { امر هم شورى بر ايى اين بود } \\
& \text { بيست مصباح از يكى روشنترست } 18 \\
& \text { اين خردها جون مصابيح انورست برد برد }
\end{aligned}
$$

Salihler güruhu ile meşveret et, peygambere gelen "onlarla meşveret et" emrini bil.

"İşleri meşveretledir" ayeti şunun içindir; çünkü meşveretle yanılma ve eğrilik azalır.

Bu akıllar parlak kandil gibiler, yirmi kandil bir kandilden daha parlaktır.

\section{D- Meşveret Yapılmayacak Kişinin özellikleri}

Mevlânâ kötülük isteyen kişilerle meşveret etmek yerine onlardan uzak durulmasını tembihleyip dost ve muhabbeti olan kişilerle meşveret edilmesini söylemektedir. ${ }^{19}$

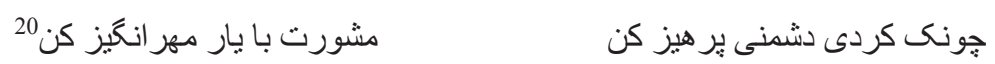

Birisine düssmanlık yaptığında ondan sakın, sana sevgi besleyen dostlarla meşveret et.

16 Mevlânâ, Mesnevî-i Ma'nevî, b. 3867, c.5, s.226.

17 Ahmed Avni Konuk, Mesnevî-i Şerîf Şerhi, c.12, s. 222 İstanbul 2005.

18 Mevlânâ, Mesnevî-i Ma'nevî, b. 2611, c.6, s.371.

19 Gölpınarlı, a.g.e, s.507, c.3-4.

20 Mevlânâ, Mesnevî-i Ma’nevî, b. 1980, c.4, s.354. 
Mevlânâ’ya göre olaylara dar görüşle bakanlarla istişâre edilmemeli çünkü bunlar kişinin kuvvetini zaafa uğratır ve kudretini kırar. Ayrıca bunların tembellikleri ve cahillikleri bulaşıcıdır. İstişârede bulunulacak kişi seni diri tutacak ve doğru yönlendirecek biri olmalıdır. ${ }^{21}$

$$
\text { كه كهين سنتم كنتد از مقدرت }
$$

$$
\text { كفت با اينها ندارم مشورت }
$$

Bunlarla istişâre etmeyeceğim dedi. Çünkü kesinlikle gücümü zayıflatırlar...

Vatan sevgisi canlarını aldatır, tembellik ve cahillikleri beni etkiler.

İstişâre etmek için seni diriltecek iyi bir diri gerek ama o diri nerede?

Mevlânâ her şeyin bir vakti olduğu gibi meşveret etmeninde bir vakti olduğunu, olmayacak zamanlarda meşveret etmenin gereksizliğini vurgulamıştır. ${ }^{23}$

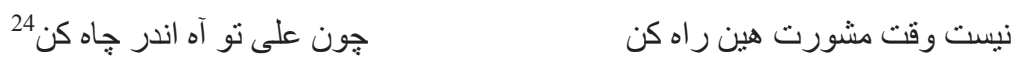

Meşveret vakti değildir, yola koyul, Ali gibi kuyuya gidip ah edip dert yan.

\section{E-Meşveret Anlayış Kazandırır}

Mevlânâ'ya göre meşveret etmek, meşveret eden kişiye anlayış ve uyanıklık kazandırır. Meşveret, meşveret edilen kişi sayısınca akılla düşünmeye yardım edip cahilliğin önüne geçer. ${ }^{25}$ İnsanların önemli işler yapacakları zaman karar vermeden önce bu konuda ihtisaslı kişilerle fikir alışverişinde bulunması gerektiğ i ve peygamberimizin önemli konularda ashabı ile istişare ettiği dile getirilmiş. ${ }^{26}$ Ayrıca Hazret-i Ali (a.s)'ın "Her kim öğretici kişilerle meşveret ederse onların akıllarına ortak olur" 27 sözü ile "Her ilim sahibinden, üstünde bir bilen bulunur" ${ }^{28}$ ve "İ̧s hakkında onlara danış" ${ }^{29}$ gibi ayetlere işâret edilmiştir. ${ }^{30}$

21 Can, a.g.e, c.3-4, s.543.

22 Mevlânâ, Mesnevî-i Ma'nevî, b. 2206 c,4, s.364.

23 Can, a.g.e, c.3-4, s.546.

24 Mevlânâ, Mesnevî-i Ma'nevî, b. 2231, c.4, s.366.

25 Ken'an Rifâi, Şerhli Mesnevî-i Şerif, Kubbealtı, s. 142, İstanbul 2010.

26 Top, a.g.e, c.1, s.608.

27 Kerîm Zemânî, Şerh-i camî-i Mesnevî-i Ma'nevî, c.1, Tahran 1375, s.356.

28 Yusuf Sûresi, 12/76.

29 Âl-i İmrân 3/159.

30 Konuk, a.g.e, c. 2 s.335. 


$$
\text { مشورت ادر اك و هشيارى دهد }
$$

Meşveret, insana idrak ve akıl verir, akıllar akla yardımcı olur.

\section{Meşveret Çeşitleri}

\section{A- Âfâkî Anlamda Meşveret}

Mevlânâ, Hz. Âdem yaratılacağı zaman Allah Teâlâ ile meleklerin meşveret ettiğgini belirtip, Bakara sûresinin; Hani, Rabbin meleklere, "Ben yeryüzünde bir halife yaratacağım" demişsti. Onlar, "Orada bozgunculuk yapacak, kan dökecek birini mi yaratacaksin? Oysa biz sana hamdederek daima seni tesbih ve takdis ediyoruz." demişler. Allah da, "Ben sizin bilmediğinizi bilirim" demisti. ayetine işâret etmiştir. ${ }^{32}$

$$
\text { مشورت مىرفت در ايجاد خلق }
$$

İnsanların yaratılması konusunda meşveret yapılırken onların canları boğazlarına kadar kudret denizine dalmıştı.

Mevlânâ'ya göre Hazret-i Havvâ'nın sözüne kanıp da yasaklanmış meyveyi yiyen Hazret-i Âdem, yemeden önce meleklerle meşveret etseydi, pişman olup özür dilemezdi. Çünkü bir akıl, başka bir akılla birleşince, kötü iş işlemekten kurtulur. Fakat ne zaman iki nefis birlikte müttefik olursa; cüz'î akıl işe yaramaz, hayırlı bir iş ve ameli neticelendirmekte aciz kalır. ${ }^{34}$ ("Hz. Âdem'in nefsi, Hz. Havvâ'nın nefsine yâr olduğu vakit, Hz. Âdem'in akl-1 cüz'îsi faaliyetten geri kaldı" Öyleyse iki nefsânî olan kimse herhangi bir konu hakkında meşveret ederse, nefsin isteğine uygun hüküm verir ve akl-1 cüz'î âtıl olarak bir tarafta kalır.) $)^{35}$

$$
\begin{aligned}
& \text { در بشيمانى نكفتى معذرت }
\end{aligned}
$$

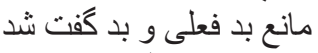

$$
\begin{aligned}
& \text { عقل جزوى عاطل و بـكار شد شُ3 }
\end{aligned}
$$

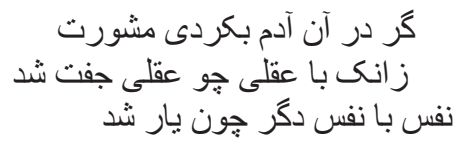

Âdem (a.s) bu konuda meşveret etseydi pişmanlık içinde özür dilemezdi.

Çünkü bir akıl başka bir akılla birleşince kötü işe, kötü söze mâni olur.

Nefis, başka bir nefisle arkadaş olursa cüzi akıl işe yaramaz ve âtıl kalır.

31 Mevlânâ, Mesnevî-i Ma'nevî, c.1. b.1044, s. 73.

32 Konuk, a.g.e, c.3, s. 71.

33 Mevlânâ, Mesnevî-i Ma'nevî, b. 170, c.2, s.231.

34 Can, c.1-2, s. 258.

35 Konuk, a.g.e, s.23 c. 3 .

36 Mevlânâ, Mesnevî-i Ma’nevî, b.19-21, c.2, s. 224. 
Mevlânâ, münkirlerin bile kendi aralarında istişâre ettiğini belirterek, Musa (a.s)'ın Firavun'a kırk gün süre verdikten sonra geri döndüğünü ve yalnız kalan Firavun'un danışmanlarını çağırıp onlarla istişâre ettiğini dille getirip Şuarâ sûresinin; Firavun, çevresindeki ileri gelenlere, "Şüphesiz bu, bilgin bir sihirbazdir" dedi. "Sizi büyüsïyle yurdunuzdan çıkarmak istiyor, Ne buyurursunuz şimdi? Dediler ki: "Onu ve kardeşini alıkoy. Şehirlere de toplayıcı adamlar gönder" 37 ayetlerine işâret etmiştir. Ayrıca Firavun'un Musa (a.s)'ın daveti hakkında Hâmân adındaki veziri ile de istişâre ettiği ifade edilmiş. ${ }^{38}$

$$
\text { جونك موسى بازكثت و او بماند الهل راى و مشورت را يبش خو اند } 39
$$

Musa (a.s) dönünce, tek başına kalan Firavun rey ve meşveret ehlini yanına çă̆ırdl.

$$
\text { جون بهامان كه وزيرش بود او }
$$

Düşmanlığı huy edinmişs olan veziri Hâmân ile meşveret edince...

\section{B- Enfüisî Anlamda Meşveret}

Mevlânâ’ya göre ilk önce, öncü ve önder olan akılla meşveret edilmedir. Nitekim peygamberlerin ümmetlerine öyle tavsiyede bulunduğunu belirtmiştir. Asla nefs-i emmâre ile meşveret edilmemesini çünkü nefs-i emmârenin kandırıcı ve yönlendirici olduğunu vurgulamış. Ayrıca nefs-i emmâre ile meşveret edilse bile onun söylediğinin aksi yapılması gerektiği dille getirilmişsir. ${ }^{41}$

$$
\begin{aligned}
& \text { انبيا كثنتد با عقل امام }
\end{aligned}
$$

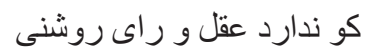

$$
\begin{aligned}
& \text { كفت امت مشورت با كى كنيم } \\
& \text { تو خلاف آن كن و در راه راه رافت } 42
\end{aligned}
$$

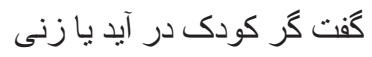

$$
\begin{aligned}
& \text { كفت با او مشورت كن وانج كفت }
\end{aligned}
$$

Ümmet; "kiminle meşveret edelim" diye sorunca, peygamberler; "önder olan akılla meşveret edin" diye cevap verdiler.

Sordular aklı veya tedbiri olmayan bir çocuk ya da kadınla da mı? koyul.

Dedi; onunla da meşverette bulun fakat ne derse onun zıddını yap ve yola

37 Şuarâ 26/34-36.

38 Konuk, a.g.e, c.5, s.310.

39 Mevlânâ, Mesnevî-i Ma'nevî, b.1157, c.3, s.79.

40 Mevlânâ, Mesnevî-i Ma'nevî, b. 1241, c.4, 319.

41 Konuk, a.g.e, c.4, s. 129.

42 Mevlânâ, Mesnevî-i Ma’nevî, b.2257-59, c.2, s. 325. 
Mevlânâ eğer danışacak kimse bulmayıp, nefsimizle bir konuyu istişâre ediyorsak, Nefsimizin söylediğinin aksine hareket etmemiz gerektiğini belirtiyor. Mesela nefis "namaz kll, oruç tut" derse bile ona inanmamamız gerektiği vurgulanmış. Çünkü nefis aldatıcıdır. İyi görünen bir emrinde bile hile yapar. Yapacağımız işlerde nefse danışmak ve o ne derse onun aksini yapmanın olgunluk olduğunu dile getirmiş. ${ }^{43}$
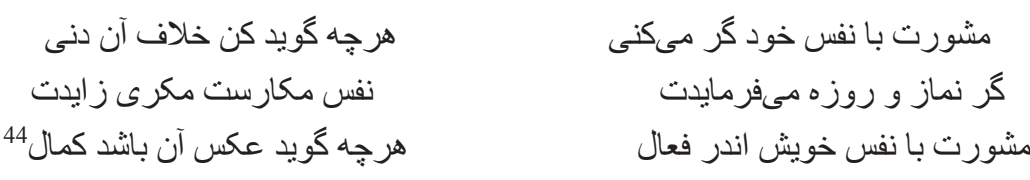

Nefsinle meşveret edersen o alçak ne söylerse tersini yap.

Ĕger sana oruç tut ve namaz kll diye emretse bile nefis hilecidir, sana bir hile kuracaktır.

İslerde nefisle meşveret etmek, ne derse onun aksini yapmak olgunluktur.

\section{Sonuç}

Toplum hayatında bireyin yalnız başına her şeyi düşünüp yapması mümkün değildir. Ortak bir aklın neticesi olan geniş kapsamlı kararlara ihtiyaç vardır. Ortak akıl ve kolektif şuur ancak meşveret ile ortaya çıkabilir. Meşveret İslam'ın üzerinde ehemmiyetle durduğu konulardan biridir. Meşveret Müslümanların sadece özel hayatlarında karşılaşacakları olayların çözümünde değil sosyal, siyasal ve idari sistemin şekillenmesi noktasında başvurmaları gereken önemli bir düsturdur. Mesnevî’de meşveret kavramına değinen Mevlânâ, meşveretin gerekliliği, meşveretin getirisi, meşveretin kimlerle yapılması gerektiği, kötü kişilerle meşveret etmenin sakıncaları, iyi düşünceli kişilerle meşveret etmenin gerekliliği gibi konuları ayet ve hadisler ışı̆̆ında açıklamıştır.

\section{Kaynakça}

Altuntaş, Halil- Şahin, Muzaffer, Kur'ân-ı Kerim Meali, Diyanet İşleri Başkanlığı Yayınları, Ankara 2003.

Can, Şefik, Konularına Göre Açıklamamalı Mesnevî Tercümesi, Ötüken Yayınları, İstanbul 1997.

Gölpınarlı, Abdülbaki, Mesnevî Tercümesi ve Şerhi, İnkılâp ve Aka Kitabevleri, İstanbul 1983.

Konuk, Ahmed Avni, Mesnevî-i Şerîf Şerhi, c.3, İstanbul 2005.

43 Gölpınarlı, a.g.e, c.1-2, s. 562.

44 Mevlânâ, Mesnevî-i Ma'nevî, b. 2261-63, c.2, s. 325. 
Çetin KASKA / İlahiyat Fakültesi Dergisi • 7 - 2017 • 97 - 106

Mevlânâ Celâleddin-i Rûmî, Mesnevî̀-i Ma'nevî, (haz. Adnan Kara ismailoğlu, Derya Örs) c.1. b.1044, Ankara 2007.

Rifâî, Ken'an, Şerhli Mesnevî-i Şerif, Kubbealtı, İstanbul 2010.

Top, H. Hüseyin, Mesnevî-i Mâ’nevî Şerhi, c.1, Konya 2001.

Türcan, Talip, “Şûra” DİA, s.230, c.39, İstanbul 2010.

Zemânî, Kerîm, Mînâger-i Işk, Neşr-1 Ney, Tahran 1393, s.825. , Şerh-i camî-i Mesnevî̀-i Ma'nevî, c.1, Tahran 1375. 